\title{
Impact of unpaved road condition on rural transport services
}

\author{
Emmerentian Mbabazi PhD \\ Research Fellow, Uganda National Roads Authority, Kampala, Uganda \\ (emtentian@gmail.com, emmerentian.mbabazi@unra.go.ug)
}

(Orcid:0000-0002-4264-2859)

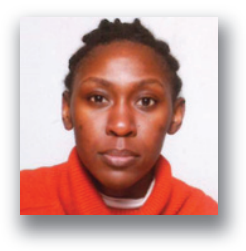

The majority of roads in developing countries especially in sub-Saharan Africa remain unpaved. To optimise their social impact, rural roads need to be complemented with convenient and affordable transport services that allow residents to reach markets and basic services. Motorcycle taxis or boda bodas, have risen to be the most dominant transport service in the rural areas of Uganda. Careful management of the vehicle operating costs (VOCs) is therefore important to sustain this service in the rural areas. This study estimates the changes in VoCs for motorcycle taxis with changes in the unpaved road condition. A $\mathbf{1 . 8 \%}$ rise in operating costs is found when a road condition deteriorates from very good to good; and a $7.7 \%$ increase when road condition deteriorates from good to fair or poor.

\section{Introduction}

Transport provision in rural Uganda has focused on the provision of roads, mostly gravel and earth roads, with the aim of enabling access to markets, and other social services. The traditional assumption governing the development of rural roads is that investment on roads will spontaneously lead to the provision of transport services by the private sector as passenger and freight operators benefit from lowered vehicle operating costs (VOCs) and travel time savings. Most road development projects in Uganda consider the benefits accrued from road improvements in terms of the reduced transport costs to road users, specifically savings on VOCs. This saving on VOC is assumed to trickle down to the wider economy through reduced travel times and transport fares. Various models have been developed to aid decision making with regard to road improvements. These models such as the roads economic decision (RED), highways design and maintenance standards (HDM III and HDM IV) relate a particular road condition with its associated VOCs. Higher VOC due to sustained deterioration of the road surface would imply that it is more expensive to move people and goods around thus reducing the amount of useful interaction between people and places further apart (Abrantes, 2015). For rural sub-Saharan Africa, where population density is usually low, reduced interaction between people and places would exacerbate the exclusion from social and civil activities, which in turn would lead to deeper poverty.

\subsection{Background and significance}

From the 1990s, motorcycle taxis - or boda bodas - have risen to be the most dominant transport service in rural areas in Uganda. Reducing the VOCs of boda bodas, therefore, is important in sustaining this business in the rural areas and optimise their social impact through the safe transportation of people and goods to health centres, schools and markets. This study estimates the changes in VOCs of boda bodas on selected roads in Eastern Uganda from 2016 to 2018, with the aim of comparing these estimates with the actual operating costs incurred.

This has two-fold significance: first, articulating the impact of delayed maintenance on the provision of and sustainability of transport services in rural areas; second, articulating the need for calibration of the evaluation models used to local conditions and particular road types in order to obtain a more accurate picture of the benefits that could accrue from road improvement or maintenance works.

\subsection{Problem statement}

There has been an expansion of boda bodas in rural areas in Uganda and together with the expansion of mobile phone services, the availability of boda boda services in remote areas give people the ability to summon transport when they need it. 
It is assumed that maintenance funding for unpaved gravel roads in rural areas aims to strike a balance between the cost of grading, re-gravelling or spot improvements and the benefits to be gained from reduced road user costs. However, due to low maintenance funding, many of the gravel roads in rural areas are not adequately maintained to a fair-to-good condition annually, leading to deterioration to poor or very poor states. Even though models such as RED can estimate the VOC for motorcycles at different road conditions, Ellis and Hine (1998) note that most VOC data used to derive the model relationships is been collected from established operators who keep good records that are inevitably located in the major cities and who use the main network of primary and secondary roads. They further note that far less is known about the true operating costs of operators travelling on the minor rural road network. No studies have been conducted to determine the actual operating costs for boda bodas and how these actual costs change with changing road conditions on unpaved gravel roads in rural Uganda.

\section{Rural transport services provision in sub-Saharan Africa}

Rural roads and transport are essential for supporting the development of agriculture, the key economic activity in rural sub-Saharan Africa. An adequate and connected rural transport network needs to be complemented with several other features to successfully provide access for all. Convenient and affordable transport services that allow rural residents to reach markets and basic services are also essential (SuM4All, 2017). Despite financial support from donors to improve rural road infrastructure, transport services in rural sub-Saharan Africa are still poor, inadequate and for most of the rural population, expensive. Ellis and Hine (1998) note that despite some road access, the rural poor in Africa still suffer from high transport costs and poor service availability with the subsequent impact that this has on all features of economic and social well-being. Porter (2013) also asserts that the lack of affordable rural transport has knock on effects on accessing schools, clinics, hospitals, markets and other social services. The poor service availability of transport services in rural areas in sub-Saharan Africa is in part due to the low population density of the rural areas coupled with low incomes. This severely reduces the effective demand for services because passenger and goods transport fares are considerably in excess of what most rural people can afford (Ellis and Hine, 1998). The different components of this high road user cost include VOCs, travel time delay, safety, comfort and convenience, and environmental impacts (Chatti et al., 2012). This study focuses on the VOCs of motorcycles. VOCs are the costs associated with owning, operating and maintaining a vehicle and include fuel consumption, oil and lubrication, tyre wear, repair and maintenance, depreciation and license and insurance.
The state of the road network affects the VOCs. The majority of roads in sub-Saharan Africa are poorly maintained and approximately 53\% remain unpaved (AfDB, 2014). VOCs can be calculated for different types of vehicles. The typical modes of transport used in rural contexts are minibuses, buses, pickups, small and medium trucks, saloon cars (or sedans), four-wheel drive vehicles, motorcycles, bicycles, donkeys, animal carts, tractors and power tillers with trailers (Hine et al., 2015). In the last 20 years, there has been a huge growth of motorcycle taxis (boda bodas) in rural areas in sub-Saharan Africa. The rise of boda bodas in rural areas today has been fuelled by the availability of cheap motorcycles imported from China (Porter, 2013). For the roads in the study area in Eastern Uganda, for example, motorcycles make up about $85 \%$ of the traffic as shown in Table 1 .

Boda bodas provide transport services between peoples' homes and the minibus, bus and truck stops where people and freight loads are consolidated, typically up to $6 \mathrm{~km}$ (Hine et al., 2015). In the study area, the boda bodas also transport people or goods to neighbouring villages, a distance ranging from 15 to $30 \mathrm{~km}$. In some cases, and during the rainy season, boda bodas are the only form of public transport available. Despite having the lowest VOCs of the motorised modes of transport mentioned previously, riders still face high operating costs. Therefore, in spite of the boda bodas dominance in rural transport services in terms of availability, they are also the most expensive means of transport per passenger or vehicle kilometre; transport fares on boda bodas are more than double that of the scarce public minibuses.

Research by Bishop et al. (2018) on the use of motorcycles and three wheelers for rural transport conducted in select villages in the central and eastern regions of Uganda note that after subtracting all expenses related to operating the motocyle taxi, the average rider's profit for a week was approximately US $\$ 8 \cdot 10$. When higher VOCs are incurred, either the rider earns less or passes this cost on to the passengers, who themselves have very low income. Nevertheless, they are the most available means of transport for people in rural areas. Starkey (2016) asserts that despite the high fares, rural people value motorcycle taxis extremely highly, due to their great availability, dependability and timeliness as they provide reliable, on-demand, point-to-point services. This, he says is also true for pregnant women, older persons and vulnerable people.

It is therefore necessary to research into ways to reduce the operating costs for boda bodas. This is under the assumption that this will reduce transport fares, making their services more accessible to the poorer rural population and therefore improve their access to further markets, health and education services. With the reduced operating costs and increased demand, other motorcycle-based three-wheelers can be adopted to carry more 
Table 1. Summary of traffic data for study roads in eastern Uganda in 2017

\begin{tabular}{lllcccccc} 
Name & Link_ID & \multicolumn{1}{c}{ Link name } & $\begin{array}{c}\text { Length: } \\
\text { km }\end{array}$ & $\begin{array}{c}\text { Surface } \\
\text { type }\end{array}$ & $\begin{array}{c}\text { Total motorised } \\
\text { traffic (including } \\
\text { motorcycles) }\end{array}$ & $\begin{array}{c}\text { Total motorised } \\
\text { traffic (excluding } \\
\text { motorcycles) }\end{array}$ & $\begin{array}{c}\text { Total } \\
\text { non-motorised } \\
\text { traffic }\end{array}$ \\
\hline C780 & C780_Link01 & Iganga-Kitayungwa & $50 \cdot 041$ & Unpaved & 1288 & 171 & 405 \\
C780 & C780_Link02 & Kitayungwa-Kamuli & $7 \cdot 185$ & Unpaved & 1288 & 171 & 405 \\
C785 & C785_Link01 & Buwenge-Nakabugu & 23.051 & Unpaved & 1288 & 171 & 405 \\
C785 & C785_Link02 & Nakabugu-Kaliro & 24.376 & Unpaved & 2032 & 115 & 463 \\
C786 & C786_Link01 & Kaliro-Kamuli & $45 \cdot 284$ & Unpaved & 1288 & 171 & 405
\end{tabular}

Source: Uganda National Roads Authority, Network Planning Department

produce and they would be more accessible to the elderly, disabled and expectant mothers.

While this paper's focus is on the relationship between road condition and VOC of boda bodas on select unpaved roads in Eastern Uganda, it is necessary to note that improving the condition of rural roads is only one of the ways to reduce boda boda VOCs. This can be complemented by, for example, subsidising spare parts or tyres for boda boda riders in rural areas. The effectiveness of any subsidy programme is dependent on fair and effective regulation of the business.

\section{Methodology}

This study investigates the changes in VOC of boda bodas in rural eastern Uganda with changes in the road condition. The study further compares the VOC estimated using RED with actual operating costs obtained from interviews with riders.

\subsection{Scope}

The study focuses on boda boda riders in three villages in Eastern Uganda: Namwendwa; Bulopa and Nakabugu. These are three of the ten villages assessed for socio-economic data for the UKAid funded project: economic growth for effective road asset management (GEM), through the research for community access program (ReCAP). The villages were chosen due to the high number of boda bodas stationed there compared with the other villages in the ReCAP study.

\subsection{Road condition data}

Road condition data were collected for five road links passing through the three villages. All these links are gravel roads. Road condition was assessed as per ReCAP project guidelines where by $5 \mathrm{~km}$ road sections are assessed on gravel loss, usable width, carriageway and side drain erosion, potholes, corrugations, rutting and impassability. The severity and extent is rated on a scale of $1-5$ as noted in Table 2. The assessed values of the severity and extent of various defects for each road section are input into a schedule to compute the functional index of the road. An average of the functional indices of each $5 \mathrm{~km}$ section of a road gives the road's functional index. For this project, the functional index is used as a measure of surface roughness and ride quality of the unpaved road. Table 3 shows the rating of the road condition in relation to the International Roughness Index (IRI) for the ReCAP GEM project. Condition data for these roads collected as part of the ReCAP project exists for 2016, 2017 and 2018.

\subsection{Using RED model}

The RED model was developed to improve the decisionmaking process for the development and maintenance of lowvolume rural roads with traffic volumes between around 50 and 300 vehicles/d. The RED software is composed of a series of Excel workbooks including two that calculate the VOCs. This study will use the HDM-4 VOCs module which defines the relationship between motorised and non-motorised vehicles operating costs and speeds to road roughness, for a particular country (Archondo-Callao, 2004). RED is suited to low volume unpaved roads as it is customised to the characteristics of unpaved roads such as the high uncertainty of the assessment of traffic, road condition and the difficulty in determining the past and/or future grading frequency of the road.

This study will use RED to estimate the monthly VOCs of boda bodas for fair-to-good road condition, for the condition

Table 2. Defects rating criteria

\begin{tabular}{|lccccc} 
& $\mathbf{1}$ & $\mathbf{2}$ & $\mathbf{3}$ & $\mathbf{4}$ & $\mathbf{5}$ \\
\hline Severity & Slight & Slight to warning & Warning & Warning to severe & Severe \\
Extent (\% of length) & $<5$ & $5-10$ & $10-25$ & $25-50$ & $>50$
\end{tabular}

Adapted from: Schedule for Road Functionality Indices, AfCAP 
Table 3. Qualitative rating against IRI

\begin{tabular}{|lcc|}
\hline IRI & Functional index $\%$ & Qualitative rating \\
\hline$<5$ & $>85$ & Very good \\
$6-11$ & $70-85$ & Good \\
$11-15$ & $50-70$ & Fair \\
$15-19$ & $30-50$ & Poor \\
$19-25$ & $<30$ & Very poor \\
\hline
\end{tabular}

Source: Workman et al. (2016)

of the road as per the assessments of 2016, 2017 and 2018. Using the responses from interviews with 14 boda boda riders, the actual monthly VOCs will be calculated and compared with the estimations.

\section{Results and discussion}

\subsection{Overview of transport services by boda bodas in selected villages}

Responses on the boda boda business in Bulopa, Nakabugu and Namwendwa were obtained from 14 riders with varying years of experience, ranging from three to 23 years. Riders reported that a litre of fuel was only sufficient for a journey of approximately $30 \mathrm{~km}$. On the selected roads (Table 1), boda boda riders' travel to other villages ranges from 11 to $42 \mathrm{~km}$ away, carrying two passengers per journey as it is most cost effective for them. They also occasionally carry small loads, approximately $100 \mathrm{~kg}$.

The socio-economic survey of the ReCAP GEM project collected data related to the time taken to travel to a district centre (DC) as well as the number of trips available to the DC. This information was mined for the three villages to compute estimations of the daily kilometers travelled and the daily hours ridden, as shown in Table 4.

\subsection{Road condition of study roads}

The study roads have gradually deteriorated with time as shown in Figure 1. In 2015, term maintenance contacts were entered into for these roads for a period of 3 years. These contracts ended by the end of 2017. This explains why the state of all the roads under this study was in good-to-very-good condition in 2016 and 2017. This has deteriorated to poor-tofair condition in 2018.

The roads are also located in a swampy area which means that certain sections easily flood during the rainy seasons leading to further deterioration as potholes and other defects are made deeper and wider. In addition to this, this area of Eastern Uganda is known for sugarcane cultivation. Large trucks usually traverse the roads collecting harvested sugarcane from the growers. During the rains, heavily loaded trucks usually leave deep gulleys at weaker sections of the roads. When that section floods, a boda boda rider cannot risk riding through since he would not be able to predict which part of the road under water is a deep gully or a pothole. In such circumstances, the rider either carries his motorcycle across, or pays others to do so. Even as the floodwaters recede from that section, it is left very slippery such that the rider is forced to move very slowly and brake very frequently. This usually leads to the use of more fuel and the faster wearing of brake pads.

\subsection{VOCs of boda bodas on the study roads}

VOCs are calculated using the RED HDM-4 VOC schedule used by the Uganda National Roads Authority (UNRA) Network Planning Department. Table 5 shows the basic input data used to compute the VOC.

The following variables in Table 5 are based on averages of responses from the 14 boda boda riders interviewed: new vehicle cost, fuel cost, lubricant cost, new tyre cost and service life. The kilometres and hours driven per year are based on the daily kilometres and hours ridden as mentioned in Section 4.1. It is estimated the riders would work at least $5 \mathrm{~d}$ a week for 52 weeks in the year, thus a 260 workday year. The rest of the variables are left as used by the UNRA Network Planning department. The VOC computed based on this basic input data is shown in Table 6 .

\subsubsection{Comparison of VOC in 2016, 2017 and 2018}

Based on Table 3 in Section 3.2, the highest VOC for a particular range of IRI is used to calculate the VOC on the study roads. An annual VOC, based on the kilometres driven

Table 4. Average daily kilometers and hours travelled by boda boda

\begin{tabular}{|c|c|c|c|}
\hline & Nakabugu & Namwendwa & Bulopa \\
\hline DC & Kamuli & Kamuli & Kamuli \\
\hline Distance to DC & 26 & 15 & 24 \\
\hline Time to DC: $\min$ & 50 & 30 & 40 \\
\hline Average daily number of trips to $D C$ & 5 & 8 & 5 \\
\hline Average daily kilometres travelled & 260 & 240 & 240 \\
\hline Average hours ridden per day & $8 \cdot 3$ & 8 & $6 \cdot 7$ \\
\hline
\end{tabular}




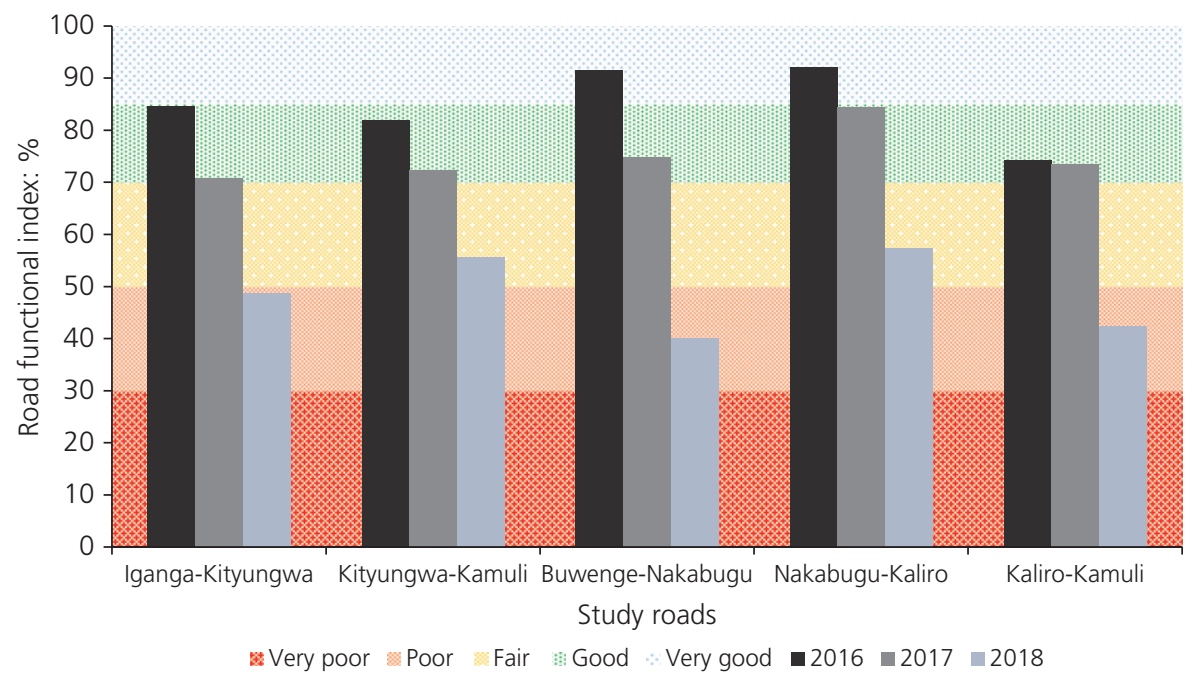

Figure 1. Functional condition of study roads for 3 years. A full-colour version of this figure can be found on the ICE Virtual Library (www.icevirtuallibrary.com)

Table 5. Basic input data to calculate VOC in RED

\begin{tabular}{lr} 
& Motorcycle \\
\hline Economic unit costs & \\
New vehicle cost (\$/vehicle) & 1184 \\
Fuel cost (\$/litre for MT, \$/MJ for NMT) & $1 \cdot 18$ \\
Lubricant cost $(\$ /$ litre) & $3 \cdot 83$ \\
New tyre cost (\$tyre) & $24 \cdot 34$ \\
Maintenance labour cost $(\$ / h)$ & 1 \\
Crew cost $(\$ / h)$ & 0 \\
Interest rate: $\%$ & 12 \\
Utilisation and loading & \\
Kilometres driven per year: km & 64000 \\
Hours driven per year: $h$ & 1993 \\
Service life (years) & 4 \\
Per cent of time for private use: \% & 10 \\
Gross vehicle weight: $t$ & $0 \cdot 2$ \\
\end{tabular}

per year in Table 5, is calculated in order to compare the actual costs reported by the boda boda riders interviewed.

Table 7 shows, as expected that the VOCs for the boda bodas is estimated to have increased as the road deteriorated. There is a $1 \cdot 8 \%$ increase in VOCs from 2016 to 2017 ranges from nil to $\$ 64$ a year. From 2017 to 2018, the change in VOC ranges from $\$ 64$ to $\$ 448$ a year, with an average of $\$ 281 \cdot 6$. This is a $7 \cdot 7 \%$ increase in VOCs. With some studies reporting the earnings of boda boda riders as $\$ 8 \cdot 10$ a week (Bishop et al., 2018), these estimates in the increase in VOC would have a very significant impact on the sustainability of this business. From 2016 to 2017, as the road condition deteriorated from very good to good, the rider would have incurred costs equivalent
Table 6. VOC computation for motorcycles in eastern Uganda

\begin{tabular}{llc}
$\begin{array}{l}\text { Code } \\
\text { (label) }\end{array}$ & \multicolumn{1}{c}{ Name (label) } & $\begin{array}{c}\text { Motorcycle } \\
\text { (\$/veh-km) }\end{array}$ \\
\hline BY-02 & Terrain B/Type Y - Roughness 02 & 0.051 \\
BY-03 & Terrain B/Type Y - Roughness 03 & 0.052 \\
BY-04 & Terrain B/Type Y - Roughness 04 & 0.054 \\
BY-05 & Terrain B/Type Y - Roughness 05 & 0.056 \\
BY-06 & Terrain B/Type Y - Roughness 06 & 0.057 \\
BY-07 & Terrain B/Type Y - Roughness 07 & 0.057 \\
BY-08 & Terrain B/Type Y - Roughness 08 & 0.057 \\
BY-09 & Terrain B/Type Y - Roughness 09 & 0.056 \\
BY-10 & Terrain B/Type Y - Roughness 10 & 0.056 \\
BY-11 & Terrain B/Type Y - Roughness 11 & 0.055 \\
BY-12 & Terrain B/Type Y - Roughness 12 & 0.056 \\
BY-13 & Terrain B/Type Y - Roughness 13 & 0.056 \\
BY-14 & Terrain B/Type Y - Roughness 14 & 0.057 \\
BY-15 & Terrain B/Type Y - Roughness 15 & 0.058 \\
BY-16 & Terrain B/Type Y - Roughness 16 & 0.059 \\
BY-17 & Terrain B/Type Y - Roughness 17 & 0.061 \\
BY-18 & Terrain B/Type Y - Roughness 18 & 0.062 \\
BY-19 & Terrain B/Type Y - Roughness 19 & 0.064 \\
BY-20 & Terrain B/Type Y - Roughness 20 & 0.066 \\
BY-21 & Terrain B/Type Y - Roughness 21 & 0.067 \\
BY-22 & Terrain B/Type Y - Roughness 22 & 0.069 \\
BY-23 & Terrain B/Type Y - Roughness 23 & 0.071 \\
BY-24 & Terrain B/Type Y - Roughness 24 & 0.073 \\
BY-25 & Terrain B/Type Y - Roughness 25 & 0.074 \\
& &
\end{tabular}

Terrain B, rolling; Type Y, gravel

to 8 weeks' worth of earnings. From 2017 to 2018, when the road condition deteriorated from good to fair/poor, the rider would have incurred costs equivalent to just under 34 weeks' from the boda boda business. Some riders interviewed noted 


\begin{tabular}{|c|c|c|c|c|c|c|}
\hline \multirow[b]{3}{*}{ Road link name } & \multicolumn{6}{|c|}{ Annual VOCs } \\
\hline & \multicolumn{2}{|c|}{2016} & \multicolumn{2}{|c|}{2017} & \multicolumn{2}{|c|}{2018} \\
\hline & $(\$ / v e h-k m)$ & Annual (\$) & $(\$ / v e h-k m)$ & Annual (\$) & $(\$ / v e h-k m)$ & Annual (\$) \\
\hline Iganga-Kitayungwa & 0.057 & 3648 & 0.058 & 3712 & 0.064 & 4096 \\
\hline Kitayungwa-Kamuli & 0.057 & 3648 & 0.057 & 3648 & 0.058 & 3712 \\
\hline Buwenge-Nakabugu & 0.056 & 3584 & 0.057 & 3648 & 0.064 & 4096 \\
\hline Nakabugu-Kaliro & 0.056 & 3584 & 0.057 & 3648 & 0.058 & 3712 \\
\hline Kaliro - Kamuli & 0.057 & 3648 & 0.057 & 3648 & 0.064 & 4096 \\
\hline Average Annual VOC & & $3622 \cdot 40$ & & $3660 \cdot 8$ & & $3942 \cdot 40$ \\
\hline
\end{tabular}

that their colleagues had left the business for farming or moved to larger towns such as Jinja due to the increasing cost of the boda boda business.

\subsubsection{Actual annual costs of running a boda boda in Eastern Uganda in 2018}

Table 8 is based on data from interviews with 14 boda boda riders. About half of the riders interviewed noted that they bought their motorcycles brand new at approximately $\$ 1184 \cdot 21$, while the other half bought second-hand motorcycles at $\$ 657 \cdot 89$. Most of the riders with new motorcycles noted that they prefer to sell off their motorcycle after one year and buy another one. This they said ensures that they keep their maintenance costs low. Riders with second-hand motorcycles tended to ride the same vehicle for up to 2 years before buying another one.

The actual cost per year from Table 8 is $\$ 32.99$ higher than the average estimate from RED in Table 7. The same values for all the economic units except 'service and other repairs' were used as the basic input data for the RED model. Any other costs incurred are based on how the rider uses his motorcycle that may have an effect on fuel efficiency and the wearing of other parts such as the brake calipers and wheel bearings. Parameters related to these effects are catered for in the RED model through the calibration data. The difference in the actual VOC obtained from Table 8 and that obtained from RED in Table 7, therefore underscores the need to calibrate the model to the different classes of the unpaved network, rather than basing on data that is usually obtained from established operators in bigger towns and cities.

\section{Conclusion}

This study set out to estimate the changes in VOCs for boda bodas with changes in the road condition; and to compare these estimates with actual costs incurred. The condition of gravel roads is known to undergo very quick deterioration in the absence of any maintenance works. This was evidenced by the steep deterioration of the study roads from 2017 to 2018 when the term maintenance contacts had ceased. The study clearly shows that changes in the road condition of gravel roads affects the VOC of boda bodas operating in Eastern Uganda. The increase in VOCs is even starker with deterioration from good to fair or poor, as was the case from 2017 to 2018. This highlights the need for continuous maintenance of the gravel roads through grading, spot improvements and other routine maintenance.

Furthermore, the difference between the actual costs incurred by boda boda riders in 2018 and the estimate from RED underscores the need to calibrate models used to local conditions for different areas even in the same country.

Although this study focused on the relationship between road condition and VOC for motorcycle taxis (boda bodas), it is necessary to reiterate that road improvement needs to be complemented with effective regulation of the business as well as other subsidy programmes in order to improve boda bodas as

Table 8. Actual VOC for boda bodas in Eastern Uganda

$\begin{array}{lrlr}\text { Economic unit } & \text { Cost: USD } & \text { Frequency } & \text { Cost per year: USD } \\ \text { New motorcycle } & 1184 \cdot 21 & 4 \text { year life span } & 59 \cdot 11^{\text {a }} \\ \text { Fuel } & 1 \cdot 18 & \text { Every } 30 \mathrm{~km} & \text { Weekly } \\ \text { Lubricant } & 3 \cdot 82 & \text { Every } 8 \text { weeks } & 198 \cdot 42 \\ \text { Tires } & 48 \cdot 68 & \text { Weekly } & 316 \cdot 45 \\ \text { Service and other repairs } & 6 \cdot 58 & & 342 \cdot 11 \\ \text { Total } & & & 3975 \cdot 39\end{array}$

${ }^{a}$ Based on double declining balance depreciation 
an essential provider of transport services in the rural areas of sub-Saharan Africa.

\section{Research paper relevance}

With motorcycle taxis (boda bodas) making up over $85 \%$ of traffic in many rural areas in Uganda and providing crucial transport services to local residents, findings from this study underscore the need for central and local governments to provide supportive frameworks that would ensure the sustainability, affordability and safety of the boda boda business. In addition, models used by the national or district road agencies to aid investment decisions such as the RED, need to be calibrated to local conditions in order to reflect a more accurate relationship between the road condition and its impact on VOCs.

\section{Acknowledgements}

The author acknowledges the financial support of UKAid through the Research for Community Access Partnership (ReCAP) project: Economic Growth through Effective Road Asset Management (GEN 2018A), from which this study obtained data. The author also appreciates the help given by: Dr. Mark H. Rubarenzya; UNRA Network Planning department in particular: Isaac Menya, Doreen Wafula, Francis Asaba; UNRA Environment and Social Safeguards department in particular: Edward Jjuko, Edith Bateganya, Bernadette Asio, Brillian Owaruhanga, Richard Odeke, Janet Awor, Maureen Okeny and Diana Akongo.

\section{REFERENCES}

Abrantes P (2015) The Funding and Economics of Highways Maintenance on Local Roads in the English City Regions. pteg Support Unit, Leeds, UK
AfDB (African Development Bank) (2014) Tracking Africa's Progress in Figures. African Development Bank, Tunis, Tunisia.

Archondo-Callao R (2004) The Roads Economic Decision Model (RED) for the Economic Evaluation of Low Volume Roads. World Bank, Washington, DC, USA, Sub-Saharan Africa Transport Program (SSATP) Working Paper Series, no. 78.

Bishop T, Barber C and Ekirapa-Kiracho E (2018) Enhancing Understanding on Safe Motorcycle and Three-wheeler Use for Rural Transport (Draft Country Discussion Paper: Uganda, RAF2114A). ReCAP for DFID, London, UK.

Chatti K and Zaabar I, National Cooperative Highway Research Program, Transportation Research Board, National Academies of Sciences, Engineering, and Medicine (2012) Estimating the Effects of Pavement Condition on Vehicle Operating Costs. Transportation Research Board, Washington, DC, USA, https:/doi.org/ $10.17226 / 22808$.

Ellis SD and Hine JL (1998) The Provision of Rural Transport Services. World Bank, Washington, DC, USA, Sub-Saharan African Transport Program (SSATP) Working Paper Series, no. 37.

Hine J, Huizenga C and Willilo S (2015) Financing Rural Transport Services in Developing Countries: Challenges and Opportunities (Discussion Paper No. GEN2016A). Research for Community Access Partnership, Oxford, UK.

Porter G (2013) Transport Services and their Impact on Poverty And Growth in Rural Sub-Saharan Africa. Africa Community Access partnership for DFID, London, UK.

Starkey P (2016) Provision of rural transport services: user needs, practical constraints and policy issues. UNESCAP Transport and Communications Bulletin for Asia and the Pacific 86: $6-22$.

SuM4All (Sustainable Mobility for All) (2017) Global Mobility Report 2017: Tracking Sector Performance. SuM4All, Washington, DC, USA.

Workman R, Otto A and Irving A (2016) The Use of Appropriate High-Tech Solutions for Road Network and Condition Analysis, with a Focus on Satellite Imagery. Reviewed Desk Study Report. Research for Community Access Partnership for DFID, Oxford, UK.

\section{How can you contribute?}

To discuss this paper, please email up to 500 words to the editor at journals@ice.org.uk. Your contribution will be forwarded to the author(s) for a reply and, if considered appropriate by the editorial board, it will be published as discussion in a future issue of the journal.

Proceedings journals rely entirely on contributions from the civil engineering profession (and allied disciplines).

Information about how to submit your paper online is available at www.icevirtuallibrary.com/page/authors, where you will also find detailed author guidelines. 